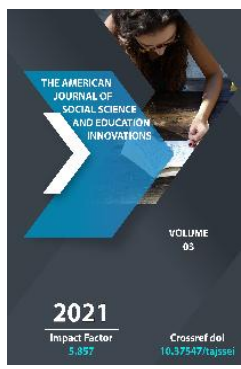

\title{
The Prevention Of Persons With A Test Period
}

Ochilov Samariddin Kamoliddinovich

The Head Of The Department Criminal Law Disciplines Of The Tashkent State University Of Law, Uzbekistan

\section{ABSTRACT}

This scientific article is intended to shed light on the theoretical aspects of the prevention of offenses of persons on probation, to identify existing problems in this area and to develop scientific and theoretical proposals for their solution. The legal foundations and scientific and theoretical description of probation, social significance, the circle of persons subject to probation, prevention of offenses of those sentenced to imprisonment, mitigation of punishment, parole. The indicators of criminal cases considered by the country's criminal courts, the number and types of crimes committed by convicts, their causes, statistics of persons released from places of detention and replaced by milder sentences have been studied. In order to increase the effectiveness of the prevention of offenses by persons on probation, the need to study the social status of a person undergoing probation, identify and eliminate his mental and physical problems is emphasized.

\section{KEYWORDS}

Probation, prevention, person, convict, sentence, court, behavior, correction, mental, physical, social, punishment, probationary period. 
The comprehensive measures have been taken in our society, prevention of offenses and crime, and the fight against safe living conditions, and significant work has been done in the positive results in law enforcement and significant stabilizing the criminogenic situation. The prevention and scientific-theoretical methods of crime and curbing crime are important in creating a decree conditions for citizens to live a secure life. In particular, the crime has been recognized as one of the topical issues facing the sentence by sentences sentenced to penitentiaries.

For this reason, the prevention of the offenses plays an important role in preventing violations, especially those who have been subjected to a pre-criminal penalty or replaced the penalty or eliminated penalty.

The changes in recent years increased the cost of testing. The research on testing went to the test, as it became clearer that the probationary period could be. Individuals were required to support the efforts of crime away from crime [16, pg. 9].

The prevention of the trial period has a unique characteristics, and such categories of individuals demonstrate the purpose of the crime not achieved, as well as the individual's self-sufficient consequences. The prevention of the offenders of certificates will be included in the terms of probation and make up a significant part of the maturation process.

Although the fight against crime and other non-social events is being done very successful, but still, to be more effective, additional preventive measures should be developed in this area to achieve the result. [1]

Most researchers describe the fight against crime from the prevention of criminals. In general, the addition of fighting crime means the context of the prevention of this offenses. If the lawmaker examines the status of individuals comply with the established restrictions and the multifaceted process, the problematic issues that need to be addressed shows that the problem needs to be addressed.

Therefore, this process requires the involvement of bodies that carry out the prevention of violations. For example, the medical and psychological problems in the person also involve other government agencies and institutions in the prevention of government agencies and institutions.

Nevertheless, working with temporary cassers are not only provided as the responsibilities of the bodies and the duties or obligations of other government agencies in the legislation. It should be noted that the restructuring of liberty is carried out in a special regime in the prevention facility, which has been introduced in a penalties. Existing criminal-criminalism exercises a mechanism for preventing the commission of crime by persons sentenced to imprisonment.

However, prevention of criminal cases, which is sentenced to non-imprisonment or the penalty, that is currently undergoing a penitentiary to study, and the development of scientific-theoretical solutions should be developed. One of the issues that is. 
The crime commission indicates that the practice of conducting it has not been fully effective through the impunity of punishment. In fact, if we mention it clearly, the conviction of a convicted person shows that the crime is a goal from the punishment.

The law draws the court to the rest of the sentence by more than the restriction of the sentence until the granted period of grantable periods, when serving the sentence. However, the issue of the legal framework remains open. The court was left simultaneously with the announcement of the replacement of this sentence. Logically, the court has such right, but it does not mean directly in the law [11, pg. 13].

The current Criminal Code and the Practition Control Codes were not provided legal. However, in practice the concept of action is used in the practice of execution of the sentence. Due to the offenses of persons convicted in the study of the prevention of the deficiencies, the prevention of persons who have been firmly controlled persons requires a special scientific-theoretical approach.

2016 of the Plenum of the Supreme Court of the Republic of Uzbekistan Resolution 28 on December 27 on the December "Release of Picture and Restoration of Replacement of the Picture" No. 28 the courts were given a number of explanations to the courts about being sentenced to passing the penalty and replacing the sentence.

In particular, the attention of the courts should not be allowed to unreasonly re-refuse, but also unconditional release or lighter replacement of prisoners or sentences.

We must also keep in mind that priority for various purposes may change. As placed on a criminal justice, the countries can change their punishment in various goals and emphasis. [2] A number of scientific-theoretical problems arise to be addressed in repeated crime in the absence of imprisonment for a sentence of imprisonment:

First, although the Institute of Contrary to the People of the Persons sentenced to imprisonment, the institution of the institute is not explored at the required level;

Second, the practical and theoretical methods for solving existing problems did not develop the prevention of persons serving sentences in the sentence of temporary probation.

Third, during the category of persons serving a penitentiary to imprisonment, a special approach is insufficient to the prevention of their offenses;

Fourth, the forecast for criminalological portrition of persons serving a penitentiary sentence was not created, and the forecast for the prevention of the criminalist whose side is possible;

Fifth, more emphasis on the mechanism of control over persons who are not related to imprisonment, and the social expectations of correction of their behavior are not widely explicited;

Sixths, treatment services, probationary controls So this, it is still possible to regulate the underlying documents, there is no integrated and constructive regulatory document. This does not allow the supervision of the probation's control over the improvement of the legislation and the introduction of new and modern mechanisms to the prevention of individuals. 


\section{MATERIALS AND METHODS}

The results of a number of scientific and theoretical views, research in the practice of free foreign scholars from foreign countries in order to improve the conviction of the profilation and delinquency were made to the practice of freedom of imprisonment.

There are mandatory symptoms such as acknowledgment of their guilt, attitudes with the risk of the convicted, to coordinate the damage, in education, compliance with labor, compliance with labor, compliance, selfdiscipline, to manage their guilt in order to be conditionally released by the convicted needed. There should be positive changes to change penitentity. In particular, personality desires to admit, attitudes with work, to work, and meet the requirements of education, compliance, discipline, and managing emotions. [12, pg. 10]

These scientific and theoretical views create a number of aspects of the organization of the prevention of offenses of persons under the affiliation of the probation. In particular, it requires that the specific socio-psychological portrait of the previously substantiated person undergoing the necessary signs that are specific to such a person's behavior.

Table 1

\begin{tabular}{|c|c|}
\hline $\begin{array}{c}\text { Necessary elements of release from } \\
\text { punishment or replacement with lighter }\end{array}$ & $\begin{array}{c}\text { Elements that are formed in the } \\
\text { prevention of personal offenses under the } \\
\text { probationary control }\end{array}$ \\
\hline In accordance with Mode requirements & Striving for self-discipline \\
\cline { 2 - 2 } partial or full repayment of the damage caused & ability to manage emotions \\
\cline { 2 - 2 } & $\begin{array}{c}\text { confession and remorse } \\
\text { Relationships to work and to study }\end{array}$ \\
\cline { 2 - 2 } & Active participation in education \\
\cline { 2 - 2 } & to engage in socially useful labor \\
\hline
\end{tabular}

The analysis of criminal cases in the criminal cases of the country over the years in the years of previous years, the study of the number and category of persons in this regard will be to draw a number of conclusions in this regard.

The legal nature of the conditional release is an incentive in the penalty. A measure of the criminal law consists of indulgence. The part of the lawful to serve the sentence within certain periods of time shall be performed during its unexecutive period. Release will move not only to another legal rules, but also takes into account that the punishment is carried out in the unofficial part of this service appointed by the court. [9, pg. 8]

The introduction of new and modern methods of the penalty, which is sentenced to nonincidentalities or the penalty (persons not to imprison their imprisonment) allowed them to achieve a positive effect. 
The following aspects of the fight against crime and prevention of the offenders of persons convicted of the offenses of persons convicted of the offender persons convicted of the defense persons are caused by the following aspects to achieve certain positive nurses:

- A separate approach to the prevention of the offenses, improving the implementation of such events, a special approach to the prevention of the offenses;

- Punishments without convictions, that is, non-liberty, deprivation, correctional labor, deprivation of correctional work), exchanged on conditional control of conditional convicted persons;

- The transition of incentives in penalties (lighter punishment, transmission of lighter punishment, transition to a suspended sentence) to the act of practical recovery.

The Institute of Punishment is of great social significance. Depending on positive changes in the conduct of the convict, the volume of criminal repression is reduced, the appropriate person against a clear person depending on the purpose of the punishment. [11, str. 13]

The extensive measures are being taken to rere-cultivate the persons who have committed a crime morally, without separating them from society. In particular, as a result of measures taken to reform the system of law enforcement, violation of violations and the fight against crime, taking into account the advanced foreign experience and international standards, have been established in our country.
The introduction of mechanisms to ensure the respect, their rights and dignity in the organization of the probation service, as well as the rights of their rights are the development of the system of education, employment of citizens, especially the employees The main task is the main task to correct their behavior without separating from society.

The creation of a new system for exercising unrelenting penalties, the supervisory persons under the supervisory parts has declined that the commission of the supervisors has decreased by the supervisors.

Analysis of the content of the normative and legal acts governing the activities of the probationary service represents a number of unique features of the mechanism of execution of such a species. Including:

- Execution of non-counter penalties is an object of activity, which is ensured that such types of punishment is executed;

- Other government agencies and organizations, as well as public structures, will be carried out in the execution of imprisonment.

- The conditional ruling and parenthesis is established on the conduct of an effective control over the released released released.

- Supervisors, as well as juvenile rejilitization and feedalyfief are provided with juvenile minors from the penitentiary institutions;

- Preventive measures should be taken to determine the risk of controlled crime;

- The study of the identity of the inspectors is carried out in the structure of the socio- 
psychological portrait, through the analysis of changes in their behavior.

The execution of the inconsistency of the terms of the application of the temporary release in a conditionally convicted person and released released persons (including release, restriction of freedom of deprivation, compulsive public affairs) is manifested in playing a non-related action measure.

Resolving social problems in the convict person is important in the prevention of the Criminal Control mechanism in the prevention of the criminal and criminal control mechanism in the prevention of the convicted personnel. The further trend of temperation, the development of development, leads to the transaction of the state structures to private partnership. In this process, "probation" is also socialized as well as the social status. In the end, the concept of "reference control" becomes a "referral service". Government orders for the private sector are formed.

Prisoners should be economically and socially independent. The competent state bodies should attract legal, medical and psychological assistance to the adaptation of those exempted from imprisonment. [17, pg. 12]

At the same time, in practice of working with the proactive convicts, there are also some elements specific to the private sector or the private sector require. These elements appear in:

First, the observance of certain restrictions by the person under the probationary (video surgery, online monitoring, information and communication technologies);
Second, qualified and special medical care for the physical and psychological recovery of the person under the probation of the person under the case (psychologist service, medical treatment, medical patronage);

Third, to take the person under the case under the probationary control (employment, vocational training).

The prevention of persons controlled by attorneys is closely implemented with the process of temption, and the involvement of the private sector of such measures is important in reducing the goal of achieving the goal. Today, the humiliation of the human sector does not yield the expected result of direct application.

Therefore, its foundation and a control mechanism should be created first. To do this, it is advisable to initiate public control over the maturation, the next stage control over the application of the private sector on the terms of the private sector.

In addition to the concept of "prevention", the concept of "fight against offenses" is used. The fight against offenses is understood, prevention, elimination, disclosure and investigation of illegal information. The prevention of offense is wider and multifaceted and is a crime that is not related or already committed. Offenses prevention means the implementation of a special complex of special events aimed at developing the fight against illegal behavior. [5, pg. 101]

While the introduction of a particular approach to the monitoring of the personality and punishable of the person (sentence) of a 
person (testing), allowance to achieve the result of the expected result gives.

The prevention of persons controlled by attorneys, is therefore important to the fact that the convict is the case, a young condition, a gender, mental state, the crime, family state, special prophylactic measures arising from the living environment and requires the introduction.

\section{RESEARCH RESULTS}

The persons who have committed a crime is the essence of the nature of the moral correction, non-discriminatory system, expresses the essence of the promotion, without separating them from society. A new system has been created for the implementation of non-liberty penalties, the conduct of influential monitoring of the supervisions of the certificates. As a result, a reduced crime was reduced by the supervisors.

As a controlled probationary period and uncontrolled test period, the prison time was to be taken into account to cancel the two. The results show that more conditions and more meetings require a high level of control. Applicant employees have been determined to call and imprison offenders. This is very important, and the most common type of trial period used in the overseer was conditional. [3, pg. 67]

In the prevention of conditional convicted persons, the probation controls also serves as a preventive event at the same time. It is also accompanied by the control of the convict (testing) during a parliamentary sentence, as well as the conduct of the convicted behavior (mental, economic, educational, etc.). The positive change observed in the conduct of the convict is a criterion for the prevalence of the prevention of the person under the application.

The researcher, according to the effective implementation of tasks related to the legal literacy and awareness of the population, plotted the need to establish a specialized special commission in which the composition is directly involved in the organization. [11, pg. 13]

Of course, along with the establishment of a specialized special commission in the formation of a specialized private commission, which is a specialized special commission on the conclusion of the profilment of the specialized commission, especially individuals, even the offenses of persons, allow us to achieve a positive result on the topic we are exploring.

In research, women's gender prisoners are invited to collect in a single penitentiary institution. A few modern smaller, technically equipped, special penitentiary institutions for women in the territory of the Republic of Uzbekistan, should be convenient for all population for women (for example, the Republic of Karakalpakstan, Tashkent, Navadarya regions and Tashkent it is emphasized. [10, pg. 21]

It is not recommended to apply the applications imposed on them in relation to the criminal prevention, administered women who have been committed or taken away from the prevention of their offenses, and to apply the same to them as well as to serve their claim. Therefore, it is expected to develop a separate and clear matters methodology in the organization of the 
prevention of women's crime under the probationary.

\section{ANALYSIS OF RESEARCH RESULTS}

The task of studying the risk of supervisors to determine the risk of reckoning and preventing the risk of preventing it, we are the basis of the problem that wants to study the problem that plans to study the sociopsychological portrait.

It is one of the important directions to achieve the goal of the offenses and obligations of the criminological strength and the obligations of the affiliates, which is the necessary and sufficient observance of the crime.

Scientific and theoretical solutions of the current persons under the study, that is, prevention of overseer problems of prevention of supervisors, are developed in the following areas:

- Study of methods for determining the risk of controlled crimes;

- Coverage of the content of preventive measures taken to commit the restructuring of

- The inspected;

- Open the mechanism of creation of the socio-psychological portrait of inspectors.

In the implementation of the preventive function of the penitentiary system, the concept of prophylaxis is in two different ways: 1) a set of measures to prevent medical sense; 2) noted that it is understood as a set of measures to prevent offenses and crime. In this sense, the prevention function of the penitentiary system is the convict, it is a set of activity and tasks that cover comprehensive measures aimed at preventing its new social dangerous acts. [14, pg. 15]

Appendix-controlled persons to prevent a set of measures aimed at preventing diseases in a medical sense in the offender profilamental and physical problems should be consolidated. It should also mean that the set of measures to prevent offenses and crimes are in harmony in the organization and implementation of reference control.

The commission of a criminal convictions sentenced by the person sentenced to the commitment of a criminal punishment is a name for the fact that the end of his behavior has been unresolved a criminal punishment. Therefore, the prevention of persons controlled by the testimony is considered as one of the topical issues that need to be explored today.

Foreign practices and research work on the activities of the application form the category of persons who may fall into the spheres of prevention of the offenses and fixed unsuccessful violations of the violation of the violation. Accordingly, we can provide the following categories of persons within the prevention of the prevention of temporary control:

Table 3

\begin{tabular}{|c|c|}
\hline First group & The second group \\
\hline those who are sentenced to & $\begin{array}{c}\text { Individuals with the physical and mental } \\
\text { problems of temperation; }\end{array}$ \\
\hline
\end{tabular}




\begin{tabular}{|c|c|}
\hline $\begin{array}{c}\text { those who have been paralyzed } \\
\text { early appointed for the crime; }\end{array}$ & $\begin{array}{c}\text { Individuals with economic and social problems } \\
\text { in the test control; }\end{array}$ \\
\hline $\begin{array}{c}\text { the penalty appointed for the } \\
\text { crime committed; }\end{array}$ & $\begin{array}{c}\text { individuals in need of rehabilitation and } \\
\text { adapting (rehabilitation) of temporary probation. }\end{array}$ \\
\hline $\begin{array}{c}\text { Filing in punishment, the persons } \\
\text { not expired. }\end{array}$ & $\begin{array}{c}\text { The problem in the formerative control, while } \\
\text { alcoholism, quarrels, quarreling, drug addiction, debtor, } \\
\text { negative) existing shots. }\end{array}$ \\
\hline
\end{tabular}

As main directions, the fight against offenses and anti-government must have a legal and moral basis. The social training of citizens, values of civil and social responsibility are. [8, pg. 170]

It should be noted that the prevention of persons-controlled persons shall not allow the maximum accident of the legal and social events in the expected result. As a result of such events, the minimum or satisfactory result can be trumpedaries. However, it is important that citizens' searning and social activity of citizens to achieve a higher result in such a type profiling.

The penalty for the moral correction of the convicit must be adapted to the criminal, not a crime. At the heart of this view, the criminal is the statement that it should not commit a crime later, and the society should ensure its rehabilitation. However, the people who have been committed in thisory are not supported by persons who are sincerely remoking. [15, pg. 20]

The person serving the penitentiary to the use of legal means, or unauthorized incorrect penitentiary or penalties, and replaced by the prevention of incentive persons, and the impunity that is not related to liberty, is certainly to take into account such positive changes in his behavior. It is also advisable that it is also one of the tools to implement the prevention of offenses.

\section{CONCLUSIONS}

The existence of private, general and theoretical features of these aspects were revealed in the field of research and profitability of profiles and the profile of the offenders of civil controlled persons.

Also, the implementation of the offenses of persons under the peratder-control police focused on identification of problems in the following areas and the development of scientific and theoretical solutions:

First, improving the organization of the prevention of the offenses of persons under the terms of the terms as a special and clear purpose;

Second, the implementation of crime prevention through the study and solution of social problems of persons within the terms of the terms.

According to the study of the study, the following suggestions will be made to improve the deficiencies of persons under the 
affiliation, supervisor, to improve the offenses of persons under the affiliate.

- Social demographic state of persons under the application, i.e. their age, marital status, place of habitat, training environment, the crime of exercises, the nature of the executive and the nature of the appointed punishment;

- Development and implementation of programs of persons subjected to the participatory inspections, neighborhoods, apartments and individual programs for the implementation of violations;

- To study and introduce the necessary mechanism for the spiritual (psychological, psychological, behavioral) and physical (health) of persons under the probationary minor;

- To involve the general public, correct their behavior and solve their behavior and solving social problems;

- Take measures to improve the economic situation in the private sector (including entrepreneurship) in the wide involvement of the fixed assuming persons;

- Expanding the participation of other government agencies and public organizations to organize the application, the effective use of tasks in the implementation of the prevention of violations;

- Use of educational institutions, in particular, in the implementation of the participation of the participation of the participation of the participation of the participation of general secondary, professional and higher education institutions;
- Formation of research on prevention of persons under the instigation of civil control, development and implementation of grant projects in this area;

- Ingrading the share of events to the development of persons control persons in sports, their teaching for their healthy lifestyle;

- Improving norms on the offenses of persons serving the sentence in special prophylacts of the Law of the Republic of Uzbekistan "On Crime Contruments".

\section{REFERENCES}

1. A.G. Repev. The State support for the right of persons without a fixed place and prevention of delinquent behavior (Based on materials of the Penza region). pg. 2. gosudarstvennoe-obespechenie-prav-litsbez-opredelennogo.

2. Joanna Shapland, Anthony Bottoms, Stephen Farrall, Fergus McNeill, Camilla Priede, Gwen Robinson. The Centre for Criminological Research, School of Law, University of Sheffield. Fergus McNeill is at the

3. John Hilgendorf. Understanding the role of probation: observing the effectiveness of probation as an alternative to incarceration in larimer county Colorado. In partial fulfillment of the requirements. For the Degree of Master of Arts Colorado State University Fort Collins, Colorado. Spring 2017. 78 pg. Pg 67.

4. University of Glasgow and Scottish Centre for Crime and Justice Research.The quality of probation supervision - a literature review. March 2012. 55 pg. Pg 2. 
5. I.I. Gerbekov. The Concept and Types of Crime prevention. The Legal Science and Law enforcement practice. 2017 №4 (42). pg. 101.

6. N.T.Tinibekov. The practice of using probation in foreign countries. The Legal Science. №5 2019. pg 54.

7. R.M. Sadikov. The Prevention of offenses as a factor in the social development of the region. International Journal of Humanities and Natural Sciences, vol.10-1 (37), 2019 (25). pg 170.

8. D.A. Sherba. The Conditional early release from serving a sentence. questions of theory and practice. The author's abstract of the dissertation on competition of a scientific degree of the candidate jurisprudence. Vladivostok, 2007. 23 pg., pg 8.

9. G.U. Ahmedova. Peculiarities of serving their liberty and its improvement. Doctor of Law (Doctor of Science) Disertility Avorator. Tashkent., 2019. pg. 75, pg. 21.

10. E.A. Kazaryan. The Conditional types of exemption from punishment. The author's abstract of the dissertation on competition of a scientific degree of the candidate jurisprudence. Moscow, 2004. 28 pg. pg. 13.

11. E.M. Abdulli. Replacement of punishment in the criminal law of Russia (legal nature, types, characteristics). The author's abstract of the dissertation on competition of a scientific degree of the candidate jurisprudence. Moscow, 2004. 27 pg. pg. 10.

12. L.V. Yakovleva. Institution of exemption from punishment in Russian law. Author's abstract of the dissertation for the degree of doctor of jurisprudence. Moscow, 2003. 56 pg. pg 4.
13. N.S. Salaev. Improving the effectiveness of the preventive function of the penitentiary system. Doctor of Law (Doctor of Science) Disertility Avorator. Tashkent., 2017 pg 60, pg 15.

14. U.Sh. Kholikulov. Theoretical foundations of improving the criminal legislation of the Republic of Uzbekistan in the context of deepening democratic reforms. Doctor of Law (Doctor of Science) Disertility Avorator. Tashkent., 2019. Page 57, pg. 20.

15. Samuel Joshua King. Going Straight On Probation: Desistance Transitions and the Impact of Probation. A thesis submitted to the University of Birmingham for the degree of Doctor of Philosophy. The University of Birmingham May 2010. pg 9.

16. V.V. Stepanov. Problems of theory and practice of parole from serving a sentence (on the example of the Tambov region). The author's abstract of the dissertation on competition of a scientific degree of the candidate jurisprudence. Moscow, 2009. 30 pg. pg. 12. 